\title{
Interactive comment on "The Relationship between Low-Level Cloud Amount and Its Proxies over the Globe by Cloud Types" by Jihoon Shin and Sungsu Park
}

Jihoon Shin and Sungsu Park

sungsup@snu.ac.kr

Received and published: 10 February 2020

Thank you very much for the very valuable comments. We have addressed all your comments and revised the manuscript following your comments. We attached a zip file, which contains a response to the comments, the tracked-change version of the revised manuscript, and supplement of the revised manuscript. Sungsu

Please also note the supplement to this comment: 
Interactive comment on Atmos. Chem. Phys. Discuss., https://doi.org/10.5194/acp-2019-560, 2019.
ACPD

Interactive comment 